\title{
Medical Management of Disasters and Mass Casualties From Terrorist Bombings: How Can We Cope?
}

\author{
Eric R. Frykberg, MD, FACS
}

J Trauma. 2002;53:201-212.

\begin{abstract}
". . from a terrorist perspective, the true genius of this attack is that the objective and means of attack were beyond the imagination of those responsible for Marine security."-Report of the U.S. Department of Defense Commission on Beirut Airport Terrorist Act, October 23, 1983
\end{abstract}

(0) ince the terrorist suicide truck bombing of the U.S. Marine barracks in Beirut in 1983, the "imagination" of Americans has continued to be taxed with devastating consistency. Explosions and bombings remain the most common deliberate cause of disasters involving large numbers of casualties, especially as instruments of terrorism, yet we still have not learned how to anticipate and manage the tragic carnage they cause with any degree of effectiveness. These attacks virtually always are directed against the untrained and unsuspecting civilian population. Unlike the military, civilians are poorly equipped or prepared to handle the severe emotional, logistical, and medical burdens of a sudden large casualty load, and thus are completely vulnerable to terrorist aims. $^{1,2}$

\section{THE CHALLENGE}

The civilian medical community in the United States has been relatively indifferent in past years to the potential threat of deliberate terrorist attacks and mass casualties. ${ }^{3}$ We have been shielded from such incidents, and thus have been spared the need to confront the unique challenges of suddenly delivering medical care to great numbers of injured victims. Our naivete and inexperience in this area have been demonstrated by the predictably confused responses to recent terrorist disasters in Oklahoma City in 1995, and in New York City, with the World Trade Center bombing in 1993 and the col-

Submitted for publication March 28, 2002.

Accepted for publication March 28, 2002.

Copyright $@ 2002$ by Lippincott Williams \& Wilkins, Inc.

From the Department of Surgery, University of Florida Health Science Center, and Division of General Surgery, Shands Jacksonville Medical Center, Jacksonville, Florida.

Presidential address presented at the 15th Annual Meeting of the Eastern Association for the Surgery of Trauma, January 16-19, 2002, Orlando, Florida.

Address for reprints: Eric Frykberg, MD, FACS, Department of Surgery, University of Florida Health Science Center/Jacksonville, 653-2 West 8th Street, Jacksonville, FL 32209; email: eric.frykberg@jax.ufl.edu.

DOI: 10.1097/01.TA.0000021586.40033.BA

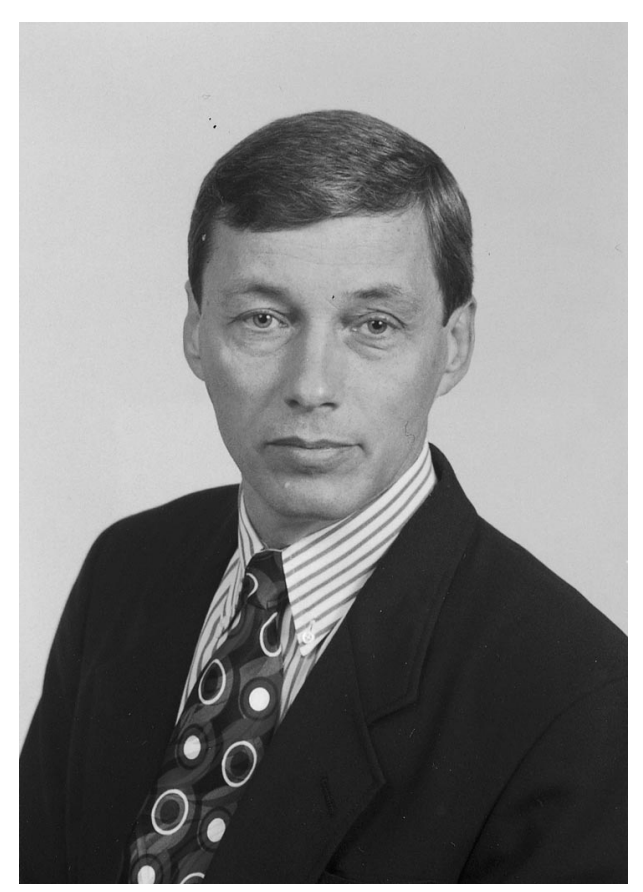

Eric R. Frykberg, MD, FACS

lapse of the World Trade Center towers on September 11, 2001.

Trauma physicians and trauma centers are uniquely qualified to play a leading role in the medical management of disaster victims and in the overall coordination of disaster response. They already are an integral part of the prehospital emergency medical system and public health efforts of many communities, and their infrastructure, training, and experience are specialized for the comprehensive evaluation and treatment of injury. ${ }^{5-7}$ However, the U.S. trauma community has not at all taken the lead in the development of disaster planning or education, which has largely defaulted to other medical specialties and administrative and public safety organizations, and has become more of a paper drill than a realistic guide for dealing with actual disasters.

Very few physicians have any experience with true mass casualty events, or disasters, which by definition involve such large numbers of victims, or such severe or unique injuries, that local medical resources cannot fully handle them. This is a very different situation from multiple casualty events, as we see on a typical busy weekend night in an urban trauma center, in which multiple patients are handled by existing 
Table 1 Casualty Flow in Disasters

Rescue
$\downarrow$
Decontamination
$\downarrow$
Sorting and life support (triage)
$\downarrow$
Evacuation
$\downarrow$
Definitive care

personnel and facilities, even if strained. ${ }^{8}$ Predictably and logically, medical response to terrorist disasters tends to be most sophisticated and most effective in those countries that most commonly are exposed to them, or among those groups who regularly train for these contingencies, such as the military. A large body of published data now exists from these unusual medical experiences that can serve as a valuable learning tool for medical communities, such as ours, in which such experience is sparse, but in which the potential for terrorist activity is on the rise. ${ }^{2,9-12}$

Military medical forces are well prepared and well trained to cope with true mass casualty events, even though they actually deal with such events as infrequently as the civilian sector. This training, and the systematic planning for orderly triage, stabilization, and evacuation of casualties through a chain of treatment stations and hospitals in times of war (Table 1), have allowed them to cope with massive casualty burdens that would overwhelm the ordinary civilian community. In the Battle of the Somme in 1916, the British military medical command was confronted with the heaviest casualty load ever documented in war, with 123,908 wounded managed by three armies in the month of July alone, 26,675 wounded seen in one 24-hour period, and 5,346 wounded soldiers treated in a single day by one casualty clearing station. ${ }^{13}$ The fact that these victims were handled in an orderly manner, even though severely straining the system, demonstrates the importance of training and preparation. The generally untrained and unprepared civilian sector must learn from this resource and from those who have handled mass casualties, because it is the civilian medical community that typically is confronted by terrorist acts.

Different types of disasters, such as fires, shootings, floods, infectious or chemical agents, radiation, or earthquakes, result in very different patterns of injury and medical needs. The purpose of this review is to define those principles that are applicable to the effective delivery of medical care after bombings and explosions, as this is the method that most commonly has been used by terrorists, and is most likely to result in the largest numbers of casualties and destruction of property. ${ }^{2}$ It also is a scenario that requires the immediate presence of surgeons and other specialists with an expertise in the management of trauma. A knowledge of the patterns of injury, and barriers to care, associated with these events, as derived from the experience of those who have been involved in true disasters, is essential to a proper response to current disasters, and to provide a template for maximizing casualty survival in the future.

\section{LEARNING FROM THE PAST Biology of Explosive Injury}

There are three forms of bodily injury induced by explosive blasts-primary, secondary, and tertiary blast injuries. Primary blast injury is caused by the shock wave that spreads radially outward from an explosion, at the speed of sound, and is transmitted more rapidly and powerfully, and over a longer distance, in water than in air. In air, this shock wave dissipates rapidly, in relation to the cube of the distance from the blast. The more powerful the blast, the greater the distance at which damage may occur. ${ }^{2,14,15}$ When the shock wave passes through the body, tissues are disrupted at airliquid interfaces in a process called "spalling," and the ears and lungs are most commonly injured. The bowels are damaged only in the most powerful blasts, most typical of underwater blasts. The degree of tissue injury is directly related to the magnitude and the duration of the peak overpressure of the blast shock wave. After this is a longer phase of negative pressure, when implosion may occur, and then a major movement of air known as "blast wind."12,16-18 Most victims of primary blast lung injury from explosions are killed immediately, as the vital organs are likely to be fatally injured in anyone who is close enough to the blast to be hit by the shock wave before it dissipates. Death is often caused by massive cerebral and coronary air embolism, as well as the most powerful forms of secondary and tertiary injuries this close in to the explosion. Late deaths among the small number of survivors with primary blast lung injury are caused by progressive pulmonary insufficiency, which has all the radiographic and pathologic signs of parenchymal hemorrhage, similar to blunt contusions. ${ }^{19,20}$

Indoor detonations tend to cause more severe primary blast injuries than open-air bombings outdoors, because the blast wave is magnified, rather than dissipated, as it is reflected off walls, floors, and ceilings. Leibovici and coworkers documented a 7.8\% mortality among 204 casualties involved in open-air bombings in Jerusalem, and a $49 \%$ mortality among 93 victims of detonations inside buses. ${ }^{12,21}$

Secondary blast injury is caused by debris set in motion by the shock wave that impacts the body. Tertiary blast injury involves the actual displacement of the victim's body to crash into other objects. These two forms of explosive injury cause typical bodily trauma, and it is these injuries that predominate among survivors of bombings. ${ }^{12,22,23}$

\section{Profile of Past Explosive Disasters}

Two major urban explosions in the 20th century, both accidental, serve to illustrate the enormous problems faced by the civilian medical community in caring for mass casualties. On December 6, 1917, a Belgian ship, the Imo, collided with the French munitions ship Mont Blanc in Halifax harbor, 
Nova Scotia, causing 35 tons of benzene to ignite on the top deck of the latter ship in a major fire. Fifteen minutes later, this fire ignited a cargo below decks consisting of 2,300 tons of picric acid, 10 tons of gun cotton, 300 rounds of ammunition, and 200 tons of trinitrotoluene (TNT), to cause the largest nonnuclear man-made explosion in history. The ship itself was blown 1 mile high, and its 2-ton anchor was found 2 miles away. Over $2.5 \mathrm{~km}^{2}$ of the city was leveled by the blast and subsequent 150-foot-high tidal wave, also wiping out hundreds of firefighters and onlookers who responded to the initial fire. The blast shattered windows $100 \mathrm{~km}$ away. There were 2,000 deaths, 9,000 injured, and 20,000 left homeless, in a city of only 50,000 population. ${ }^{24}$

On April 16, 1947, the ship Grand Camp caught fire in the port of Texas City, Texas. Twenty minutes later, its cargo of ammonium nitrate fertilizer exploded, shooting a column of smoke 2,000 feet into the air, and hurling the ship's 1.5-ton anchor 2 miles away. Shortly after this was another more powerful blast, followed by a 150 -foot-high tidal wave and numerous fires throughout the area. There were 600 deaths in a city of only 16,000 population, including, once again, the loss of the city's entire fire department and dozens of onlookers who responded to the initial fire. ${ }^{25}$

These disasters demonstrate how a typical community's medical resources would be overwhelmed by such large casualty loads, especially if medical facilities also were destroyed. Medical management of such great numbers must depend on help from outside, and on the ability to evacuate victims to other facilities and other locations for definitive care (Table 1). ${ }^{7}$ The panic, chaos, and emotional trauma of such disasters can magnify the loss of life, and are best combatted by prompt and vigorous leadership, and a preexisting plan for the immediate rescue, disposition, and treatment of casualties. ${ }^{26}$

Also demonstrated was the importance of protecting medical assets by keeping them away from the explosion scene and areas at high risk of further attack and damage. The "second-hit" principle was well illustrated in these incidents, involving the attraction of first responders and onlookers by an initial fire or explosion, who then are wiped out by a subsequent blast or other force. Terrorists have learned to exploit this to great effect, and this has become a common pattern in terrorist bombings to maximize injury and fear. The fact that first responders typically include firefighters, police, and medical personnel, who are trained to help victims, emphasizes the danger of this phenomenon to subsequent rescue and care efforts, and the importance of avoiding it by restricting the initial response. ${ }^{2,5}$

Terrorism is the unlawful exercise of random and ruthless violence against property or individuals, usually innocent civilians, to intimidate governments or societies for political or ideologic purposes. ${ }^{27}$ The devastation caused by explosions has led to this becoming the most common deliberate weapon of terrorism. The first recorded terrorist bombing occurred in Antwerp, Belgium, in 1585, when 7 tons of
Table 2 Prominent Terrorist Bombings Since 1969

\begin{tabular}{lc}
\hline \multicolumn{1}{c}{ Event } & Year \\
\hline Cu Chi, Vietnam & 1969 \\
IRA Bombings, U.K. & $1970 \mathrm{~s}$ \\
PLO in Israel & $1970 \mathrm{~s}$ \\
Bologna, Italy & 1980 \\
U.S. Marines, Beirut & 1983 \\
Paris bombings & 1986 \\
Lockerbie Pan Am crash & 1988 \\
World Trade Center & 1993 \\
AMIA, Buenos Aires & 1994 \\
Oklahoma City & 1995 \\
Atlanta Olympics & 1996 \\
U.S. Embassies, Africa & 1998 \\
World Trade Center collapse & 2001 \\
\hline
\end{tabular}

gunpowder were detonated to destroy a bridge on the River Schelt, reportedly killing 1,000 soldiers, among whom “.. some dropped dead without any wounds, sheerly from concussion." "This is probably the first known description of primary blast injury. The number and destructive power of bombings reached a zenith in the 20th century. There was a 10-fold increase in terrorist bombing incidents worldwide between 1968 and 1980, with 5,075 events documented between 1973 and 1983, causing 3,689 deaths and 7,991 injuries. $^{28}$

Even in the United States, there were 12,216 bombing incidents just between 1980 and 1990. This trend continued increasing during the $1990 \mathrm{~s}$, with 1,582 bombings causing 222 injuries and 27 deaths in the United States in 1990 alone. ${ }^{3,11,29}$ However, Americans have continued to feel immune to any significant impact from bombings until relatively recently (Table 2 ).

The first major loss of American lives from this form of attack occurred with the truck-bombing of the U.S. Marine barracks in Beirut, Lebanon, in October 1983. The detonation of an ammonium nitrate fuel-air bomb resulted in an explosive force equivalent to 6 tons of TNT, the largest nonnuclear man-made explosion ever detonated deliberately. This caused the complete collapse of the four-story building, with 346 casualties, including 234 (68\%) immediate deaths and 112 survivors. The onshore battalion aid station was located on the fourth floor, and its physician and several corpsmen were killed. Initial rescue efforts were hampered by hostile sniper fire. Sixty-five survivors were treated by an on-site U.S. Navy surgical team aboard a ship located offshore in the first 6 hours after the incident. A total of 86 survivors were then evacuated to Germany, Italy, and Cyprus for definitive care. $^{30-32}$

Analysis of the patterns of injury and death from this event demonstrates some important principles relating to disaster management. Most survivors had noncritical injuries. Nineteen survivors $(17 \%)$ were critically injured (Injury Severity Score [ISS] > 15), among whom seven (37\%) deaths ultimately occurred days to weeks later. Six of these deaths 
$(86 \%)$ were in victims who were rescued and treated more than 6 hours after the blast ( 2 had severe burns), whereas only 1 occurred, from blast lung injury, among all 65 survivors rescued early. This emphasizes the importance of a short interval between injury and treatment, and early aggressive resuscitation, as a prognostic factor for survival. ${ }^{1,32}$

The high immediate death rate $(68 \%)$, and the high dead/wounded ratio of $>2: 1$ (which is a reversal of the 1:2-1:5 ratio typical of military combat in conventional wars) was probably because of the extreme magnitude of the explosive force and the added impact of building collapse. Both of these are major prognostic factors of terrorist bombings that affect casualty outcome. ${ }^{28}$ The high death rate among the critically injured survivors (7 of 19 [37\%]) also can be attributed to these factors. This "critical mortality rate" more accurately reflects the magnitude of the disaster and results of medical management than the overall mortality rate of $6.3 \%$ (7 of 112), as it measures deaths among only those truly at risk of death. The overall mortality rate is falsely diluted by the majority of noncritical survivors. ${ }^{32,33}$

Most survivors of the Beirut bombing suffered soft tissue and musculoskeletal injuries, which were relatively mild and not life threatening. Head trauma was the most common injury among immediate (71\%) and late deaths (57\%), but only $11 \%$ (4 of 37) of those with head injuries died. ${ }^{30}$ Chest trauma (including blast lung) and burns occurred in only a small number of survivors, but were major contributors to late deaths (29\% each), and had the highest specific mortalities (15\% and $40 \%$ mortality, respectively, among all survivors with these injuries). These data indicate the importance of anatomic site and nature of injury as a prognostic factor among bombing victims, and may be useful in comparing different bombing disasters with respect to medical needs and how medical care may affect outcome. Also demonstrated in this incident were the dangers of placing medical assets in front-line high-risk areas, the potential for first responders to be killed by a second-hit phenomenon (in this case, sniper fire), and the need to triage and manage casualties at a site distant from the disaster scene. ${ }^{5}$

The importance of an immediate presence of surgical capability, and an established evacuation plan, were other lessons learned in the Beirut experience. Survivors of bombings can be expected to have a variety of injuries from secondary and tertiary blast effects, for which surgery is likely to be necessary in the most seriously wounded. Two laparotomies were performed within hours of the bombing by the on-site surgical team in Beirut, and most evacuated survivors required rapid resuscitation and surgery over the next 3 days. ${ }^{32}$ These factors undoubtedly saved lives among the most critically injured survivors.

Several other terrorist bombings that primarily involve indoor detonations have been documented in the published literature (Table 3). It is worthwhile to review the results of these events to confirm the importance of the lessons learned in Beirut, and delineate any other factors that may impact on
Table 3 Primarily Indoor Terrorist Bombings

\begin{tabular}{lcccc}
\hline Event & $\begin{array}{c}\text { No. of } \\
\text { Total } \\
\text { Casualties }\end{array}$ & $\begin{array}{c}\text { No. of } \\
\text { Immediate } \\
\text { Deaths (\%) }\end{array}$ & $\begin{array}{c}\text { No. of } \\
\text { Critically } \\
\text { Injured (\%) }\end{array}$ & $\begin{array}{c}\text { No. of } \\
\text { Survivor } \\
\text { Deaths (\%) }\end{array}$ \\
\hline Cu Chi $^{34}$ & 46 & $12(26)$ & $3(9)$ & $3(9)$ \\
Bologna $^{23 * *}$ & 291 & $73(25)$ & $48(22)$ & $11(6)$ \\
Beirut $^{32 * *}$ & 346 & $234(68)$ & $19(17)$ & $7(6)$ \\
Paris $^{28}$ & 268 & $13(5)$ & $40(16)$ & $7(3)$ \\
AMIA $^{35 * *}$ & 286 & $82(29)$ & $14(7)$ & $7(3)$ \\
Oklahoma City $^{36 * *}$ & 759 & $162(21)$ & $52(9)$ & $5(0.8)$ \\
$\quad$ Total & 1,996 & $576(29)$ & $176(12.5)$ & $40(3)$ \\
\hline
\end{tabular}

* Percentage of total survivors.

** Involved major element of building collapse.

the effective delivery of medical care in these unique circumstances.

In August 1980, the railroad terminal in Bologna, Italy, was bombed during rush hour with an explosive device of 20 $\mathrm{kg}$ of TNT, causing a partial building collapse. There were 291 casualties, 73 (25\%) of which were immediately killed. Although $83 \%$ of the 218 survivors were hospitalized, only $48(22 \%)$ were critically injured, in which group 11 deaths occurred (6\% overall mortality, $23 \%$ critical mortality rate). ${ }^{23}$ The occurrence of building collapse, and an injury pattern of largely noncritical soft tissue and musculoskeletal trauma, were similar to the Beirut bombing. The percentage of critically injured survivors was also similar. The ISS distributions of survivors from both events were remarkably similar, with a mean ISS in both incidents of approximately $11 .{ }^{32}$ The lower immediate death rate, and the lower but still substantial critical mortality rate, in the Bologna incident, were probably because of the weaker explosive force and the building collapse affecting only a portion of the casualties, with much of the blast dissipated through the open air of the spacious building. The large casualty load was the result of the large number of people in the building at the time.

A series of 11 terrorist bomb explosions occurred in Paris, France, during a 10-month period in 1986, all but one occurring indoors. Five events produced more than 30 casualties each. A total of 268 casualties occurred, with $13 \mathrm{im}$ mediate deaths $(5 \%)$ and 205 of the 255 survivors hospitalized. Forty survivors were critically injured (16\%), among whom seven died (17.5\% critical mortality, $3 \%$ overall mortality). The average ISS of all survivors was 14.8 , but among the seven late deaths it was $39.8 .^{28}$

An explosive device of $10 \mathrm{~kg}$ of TNT was detonated during the noon meal in a U.S. military mess hall in $\mathrm{Cu} \mathrm{Chi}$, Vietnam, in 1969, resulting in 46 casualties, including 12 immediate deaths (26\%). Twelve of the 34 survivors were evacuated to U.S. Army hospitals (35\%), among whom 3 $(25 \%)$ died. $^{34}$

In 1994, a seven-story building in Buenos Aires, Argentina, which housed the Argentine Israeli Mutual Association (AMIA), was leveled by the detonation of an ammonium nitrate fuel-air explosive device with a blast force equivalent 
Table 4 Impact of Building Collapse on Outcome in Oklahoma City Terrorist Bombing, 1995*

\begin{tabular}{lcccc}
\hline $\begin{array}{c}\text { Casualty } \\
\text { Location }\end{array}$ & $\begin{array}{c}\text { No. of } \\
\text { Casualties }\end{array}$ & $\begin{array}{c}\text { No. of } \\
\text { Dead (\%) }\end{array}$ & $\begin{array}{c}\text { No. of } \\
\text { Survivors }\end{array}$ & $\begin{array}{c}\text { No. of Survivors } \\
\text { Hospitalized (\%) }\end{array}$ \\
\hline Collapsed & 175 & $153(87)$ & 22 & $18(82)$ \\
Uncollapsed & 186 & $10(5)$ & 176 & $32(18)$ \\
$\quad$ Total & 361 & $163(45)$ & 198 & $50(25)$ \\
\hline
\end{tabular}

* Includes only 361 casualties inside the Murrah Building, stratified by portion of building in which they were located. From Mallone et al., $1996 .^{36}$

to $660 \mathrm{lb}$ of TNT. ${ }^{35}$ There were approximately 286 total casualties and $82(29 \%)$ immediate deaths. Among the 204 survivors, $41(20 \%)$ were hospitalized, $14(7 \%)$ were critically injured, and 4 of these died, for an overall late mortality of $3.4 \%$ and a critical mortality rate of $29 \%$. The most severely injured were those within the building at the time of the bombing.

In 1995, an ammonium nitrate bomb designed as a fuelair explosive (similar to the explosions in Texas City, Beirut, and Buenos Aires) was detonated in front of the Murrah Federal Building in Oklahoma City, Oklahoma, with a blast force equivalent to 2 tons of TNT. ${ }^{36}$ This caused a partial collapse of the building and damage to several surrounding buildings. There were 759 total casualties, 162 (21\%) immediate deaths, $83(14 \%)$ hospitalized survivors, and $52(9 \%)$ critically injured survivors, among whom there were 5 late deaths $(0.8 \%$ overall mortality among all 597 survivors, $9.6 \%$ critical mortality rate). As in the AMIA bombing, the highest mortality and most severe survivor injuries occurred in the victims in the collapsed portion of the building (Table 4).

The collapse of the twin towers of the World Trade Center in New York City on September 11, 2001, was devastating in terms of how unexpected it was, and the realization of how vulnerable the United States is to such attacks. The jetliner crashes into these buildings, quite analogous to bombings, are estimated to have imparted the equivalent of 12,500 tons of force. The subsequent building collapse is estimated to have released the equivalent explosive force of 900 tons of TNT, ${ }^{37}$ resulting in approximately 3,000 deaths, and several hundred survivors with predominantly noncritical injuries (dead/wounded ratio of 5:1). With only a few survivors rescued from the collapsed buildings, the immediate death rate among those in the buildings was over 99\%. Complete information on severity of injuries and mortality among survivors is not yet available.

The published casualty figures and outcomes from several bombings that were primarily outdoors ${ }^{10,12,18,38-42}$ all demonstrated similar patterns of predominantly noncritical injuries, but had relatively low immediate and late mortality. ${ }^{33}$ Analogous results were reported after the bombing at the 1996 Olympics in Atlanta, Georgia, ${ }^{43}$ although the major injuries from this incident were penetrating wounds from strewn shrapnel, somewhat different from the blastrelated blunt trauma of most other bombings. All these events
Table 5 Relation of Explosive Force and Building Collapse to Casualty Outcome*

\begin{tabular}{lcccc}
\hline \multicolumn{1}{c}{ Event } & $\begin{array}{c}\text { TNT } \\
\text { Equivalent } \\
\text { (Tons) }\end{array}$ & $\begin{array}{c}\text { Immediate } \\
\text { Deaths (\%) }\end{array}$ & $\begin{array}{c}\text { Critical } \\
\text { Survivors } \\
(\%)\end{array}$ & $\begin{array}{c}\text { Critical } \\
\text { Mortality } \\
(\%)\end{array}$ \\
\hline Bologna $^{23}$ & 0.04 & 25 & 22 & 23 \\
Beirut $^{32}$ & 6 & 68 & 17 & 37 \\
AMIA $^{35}$ & 0.33 & 94 & 34 & 29 \\
Oklahoma City $^{36}$ & 2 & 87 & 82 & 28 \\
WTC 9/11/01 & 900 & $>99$ & $?$ & $?$ \\
\hline
\end{tabular}

WTC, World Trade Center.

* Includes only those casualties in collapsed portion of buildings.

occurred in major urban settings, with several nearby hospitals and extensive medical resources available, and involved relatively small bombs with rapid blast dissipation within a short distance in the outdoor environment. These are probably the major factors contributing to the low critical injury and mortality rates of these incidents.

\section{Patterns of Injury, Severity, and Mortality}

It is important to distinguish the two goals of terrorist attacks: casualty generation, or the total number injured and killed from the single use of a weapon; and lethality, or the proportion of casualties killed. The magnitude of an explosion, and the number of people in the vicinity, primarily determine casualty generation, whereas indoor location and building collapse maximize lethality. ${ }^{3}$

Analysis of past bombing disasters reveals definite patterns of injury and mortality, which provide the opportunity to plan and prepare for future events. Immediate deaths, or those who die before reaching medical care, appear related to the magnitude of the explosion, the occurrence of building collapse, and an indoor location (Table 3). A comparison of those bombings involving a major component of building collapse shows substantial rates of immediate deaths, and relatively constant critical mortality rates among survivors, with widely varying explosive forces (Table 5). Those incidents involving an additional component of indoor location were associated with the highest immediate death rates. This suggests that building collapse is the most important determinant of outcome among these variables. Indoor blasts not only magnify the destructive power of the primary blast shock wave but also promote complete building collapse, which maximizes both casualty generation and lethality of a bombing. ${ }^{12,18,21,34,42}$

A greater magnitude of explosive force tends to maximize casualty generation, even in outdoor locations, but the rapid dissipation of the shock in open air reduces lethality, with a lower level of critical injuries among survivors. The open-air bombings at Old Bailey, the Tower of London, and Jerusalem in the 1970s, and at the 1996 Olympics, support this observation. ${ }^{11,40,41,43}$ This was also illustrated in the Oklahoma City bombing in 1995, in which a very large 2-ton TNT equivalent blast was primarily directed through the air 
because the truck-borne bomb was placed outside the target building. This resulted in 759 casualties, but only $9 \%$ suffered critical injuries, and there was only a $9.6 \%$ critical mortality rate. ${ }^{36}$ However, those casualties within the collapsed portion of the building suffered significantly higher mortality and morbidity (Table 4). The virtually $100 \%$ immediate death rate of casualties within the collapsed World Trade Center towers clearly showed the relative importance of building collapse, over and above explosive force, as a prognostic variable. The magnitude of explosive force has its greatest impact on lethality, rather than only casualty generation, when it is applied to building collapse, and when greater than a 1-ton TNT equivalent. The largest buildings, containing the greatest numbers of potential casualties, require the largest levels of explosive force to collapse. In both Buenos Aires and Oklahoma City, mortality was highest on the upper floors of the collapsed building. ${ }^{35,36}$ Building collapse is also maximized by placing the bomb completely within the building, as occurred in Beirut, Bologna, and Buenos Aires, rather than outside to result in partial collapse, as in Oklahoma City.

Another determinant of mortality among victims of bombings is the availability of medical resources at the disaster scene. One reason for the high immediate death rate and critical mortality rate in Beirut was its isolated location in a hostile country without an established prehospital system of transport and care, and without secure definitive care facilities, requiring a long time interval for rescue and transport of survivors to British and American military hospitals in Cyprus, Italy, and Germany. ${ }^{31,32}$ This same problem occurred in the $\mathrm{Cu}$ Chi mess hall bombing in Vietnam. ${ }^{34}$ In contrast, bombings in major urban areas with extensive and sophisticated prehospital systems and medical facilities, which allow rapid rescue and transport to definitive care, tend to have lower mortality rates. ${ }^{12,23,28,35,36,38,42,43}$

Most critical body system injuries are found among those immediately killed after terrorist bombings. Although all fatalities suffered multiple injuries, head injuries tend to be most common in this group, as was shown in Beirut. ${ }^{30}$ Data from 305 fatalities from the Northern Ireland bombings in the $1970 \mathrm{~s}^{12,18,38}$ showed that primary blast lung was found in $47 \%$, abdominal injuries in 34\%, and other chest injuries in $25 \%$ of all immediate deaths. These are the same body systems that most commonly cause death in all other forms of trauma. Among survivors, soft tissue and musculoskeletal injuries, and blast injuries of the ears and eyes, predominate in up to $80 \%$ of cases, but are mostly noncritical in severity, and contribute virtually nothing to mortality. ${ }^{23,32,33,36} \mathrm{Al}$ though over $50 \%$ of deaths among immediate survivors of bombings have head injury, most survivors with head injuries are noncritical, as only $1.5 \%$ of those with head injuries die. ${ }^{18,30,33}$ The most critical cases are selected out by the initial blast, succumbing to immediate death. Chest and abdominal injuries, including blast lung, and traumatic amputations, occur very infrequently among bombing survivors for the same reason. ${ }^{2}$ However, the few surviving cases of these injuries have a substantial specific mortality, with $19 \%$ of all surviving abdominal injuries, $15 \%$ of chest injuries, and $11 \%$ of blast lung cases and traumatic amputations succumbing to late death despite medical care. ${ }^{2,10,18,28,33}$ These injuries should be recognized as prognostic markers of severity, and need immediate care to optimize survival. Burns also are relatively infrequent among survivors of bombings, and tend to be mild flash burns, with low mortality. ${ }^{33}$ In some bombings, however, burns have been more severe and a larger contributor to mortality, as in Beirut, where $40 \%$ of burned survivors died. ${ }^{32}$ Over 20 survivors of the World Trade Center disaster on September 11, 2001, were transported to a burn center with severe burns.

The anatomic distribution of injuries among bombing victims tends to be out of proportion to the total body surface area. Head injuries occur more frequently than would be predicted on the basis of the $12 \%$ body surface area of the head and neck exposed to the environment, whereas torso and extremity trauma occur less frequently than their relative surface areas would suggest. This has been explained by clothing distribution, with covered areas of the body being less exposed to some of the forces of injury, such as flash burns. ${ }^{10-12,23,33,44-46}$

Emotional shock is a common consequence of terrorist bombings, especially among female survivors. Although it is not as lethal as physical injury, there is significant potential for long-term psychological disability. This should be considered in the same category as other major injuries with respect to the need for treatment. Disaster planning should include provisions for emotional evaluation and rehabilitation of casualties. ${ }^{10,38,44}$

One of the most consistent injury patterns noted among survivors of terrorist bombings is the overwhelming predominance of relatively minor, noncritical injuries that are not life-threatening. ${ }^{9,23,32,33,35,36,43,47}$ The incidence of critical injuries among survivors varies between $9 \%$ and $22 \%$ (Table 3 ). The planning for medical management of casualties must revolve around this basic lesson learned from prior bombing disasters, as medical resources must be allocated accordingly. Another implication of this pattern is the importance of expressing late deaths in terms of the critical mortality rate rather than the artificially skewed overall mortality rate, as mentioned previously, because of the false dilution of the latter by the majority of non-life-threatening injuries among survivors (Table 3 ). The critical mortality rate should be a more accurate reflection of the adequacy of medical care, and of the impact of those variables affecting outcome, such as explosive force or building collapse (Table 5). It is also a better figure to use in comparing the outcome from different disasters. ${ }^{33}$ Any death that occurs among noncritical survivors should be analyzed as an important audit filter in assessing the quality of medical management. 


\section{The Concept and Importance of Triage}

Triage, or the prioritizing of patients according to injury severity and the need for immediate care, is seldom practiced to any significant degree in the normal everyday management of trauma in the United States. Physicians have largely forgotten the principles of triage. All injured patients are brought to hospitals, and extensive resources are applied to every injury to maximize the benefit to each individual. However, triage must assume great importance in mass casualty scenarios in which the large numbers of casualties overwhelm existing medical resources. ${ }^{1}$ The challenge of triage in this setting is to identify that minority of casualties who are critically injured and require immediate care, from among the great majority of casualties who are not critically injured. The greater the number of casualties, the more difficult this becomes, the more time it may take to find those needing immediate care, and the greater the likelihood of preventable deaths caused by delay in treatment of the most severely injured.

There are four generally accepted standard triage categories: first, casualties requiring immediate treatment, such as hypotension, airway compromise, active external hemorrhage, open chest wounds, and intermediate burns; second, injuries requiring treatment, but in whom delay is acceptable, such as open extremity fractures, extremity vascular injuries, and soft tissue wounds; third, minimal injuries requiring no treatment (walking wounded); and finally, expectant injuries, or those that are so severe and require such time and resources that it is not possible to provide care without jeopardizing other more salvageable victims, and which therefore should not receive care, such as severe head injury, open skull fractures with extruding brain, cardiac arrest, and extensive and deep burns. ${ }^{5,7,26,33,47,48}$ This latter category most typifies the basic change in mindset necessary in mass casualty management from our normal management of trauma, from the greatest good for each individual to the greatest good for the greatest number. Treatment of a population must supplant treatment of individuals. This mandates that some survivors should not be treated, even though possibly salvageable, a concept that is foreign to our training in health care delivery. The decision as to what specifically constitutes an expectant injury must be individualized according to the numbers and types of casualties, and the available resources, and requires some advance planning and knowledge of mass casualty principles.

Rapid and accurate triage, to detect and treat the most critical injuries in the shortest time, could significantly minimize mortality among bombing survivors. Undertriage, or the assignment of critically injured casualties needing immediate care to a delayed category, is a medical problem that could lead to preventable deaths. It always should be avoided by proper training of triage officers to recognize life-threatening problems. ${ }^{49}$ The results of virtually all published ter-
Table 6 Relation of Overtriage to Critical Mortality in Terrorist Bombing Survivors

\begin{tabular}{|c|c|c|c|c|c|}
\hline Event & Year & $\begin{array}{l}\text { No. of } \\
\text { Survivors }\end{array}$ & $\begin{array}{l}\text { No. of } \\
\text { Critically } \\
\text { Injured } \\
(\%)^{\star}\end{array}$ & $\begin{array}{c}\text { No. of } \\
\text { Overtriage } \\
(\%)^{\dagger}\end{array}$ & $\begin{array}{l}\text { No. of } \\
\text { Critical } \\
\text { Mortality } \\
(\%)^{\star \star}\end{array}$ \\
\hline $\mathrm{Cu} \mathrm{Chi}^{34}$ & 1969 & 34 & $3(9)$ & $9(75)$ & $1(33)$ \\
\hline Craigavon $^{38}$ & 1970s & 339 & $113(33)$ & $29(20)$ & $5(4)$ \\
\hline Old Bailey ${ }^{40}$ & 1973 & 160 & $4(2.5)$ & $15(79)$ & $1(25)$ \\
\hline Guildford $^{12}$ & 1974 & 64 & $22(34)$ & $2(8.3)$ & 0 \\
\hline Birmingham $^{42}$ & 1974 & 119 & $9(8)$ & $12(57)$ & $2(22)$ \\
\hline $\begin{array}{l}\text { Tower of } \\
\text { London }^{41}\end{array}$ & 1974 & 37 & $10(27)$ & $9(47)$ & $1(10)$ \\
\hline Bologna $^{23}$ & 1980 & 218 & $48(22)$ & 133 (73.5) & $11(23)$ \\
\hline Beirut $^{32}$ & 1983 & 112 & $19(17)$ & $77(80)$ & 7 (37) \\
\hline $\mathrm{AMIA}^{35}$ & 1994 & 200 & $14(7)$ & $47(56)$ & $4(29)$ \\
\hline $\begin{array}{c}\text { Oklahoma } \\
\text { City }^{36}\end{array}$ & 1995 & 597 & $52(9)$ & $31(37)$ & $5(10)$ \\
\hline Total & & 1,880 & $294(16)$ & 364 (53) & $37(12.6)$ \\
\hline
\end{tabular}

* Percentage of total survivors.

${ }^{\dagger}$ Number of noncritical survivors triaged to immediate care, as a percentage of all casualties triaged to immediate care.

${ }^{* *}$ Number and percentage of all critically injured survivors who died.

rorist bombings demonstrate this goal has been achieved, with no reported case of undertriage. $23,31,33,35,36,43$

Overtriage, or the proportion of survivors assigned to immediate care, hospitalization, or evacuation who are not critically injured, is considered more an administrative, logistical, and economic problem under ordinary circumstances, since expensive and limited hospital resources and man-hours are applied unnecessarily. ${ }^{49-51}$ Generally, an overtriage rate of $50 \%$ is considered necessary to reduce potentially life-threatening undertriage to zero, and this is accepted by trauma centers under normal circumstances as a necessary price to pay to avoid missing injuries that should be found. ${ }^{8,33,52}$ However, in a mass casualty disaster, it is reasonable to postulate that overtriage could be as life-threatening as undertriage, because of the inundation of overwhelmed medical facilities with large numbers of noncritical casualties all at once, which may prevent the timely detection of that small minority with critical injuries who need immediate treatment, and jeopardize their survival. ${ }^{33}$ A compilation of published data from 10 terrorist bombing incidents, or groups of incidents in a common location involving a single hospital or medical facility, from which overtriage and critical mortality rates can be determined, demonstrates that overtriage ranged from $8 \%$ to $80 \%$, averaging $53 \%$, and critical mortality ranged from $0 \%$ to $37 \%$, averaging $12.6 \%$ (Table 6 ). The direct linear relationship between overtriage and critical mortality in these disasters (Fig. 1) confirms that overtriage can result in the loss of potentially salvageable lives in this setting. These data establish the importance of triage accuracy and triage discrimination (i.e., minimizing both undertriage and overtriage) as a major determinant of casualty 


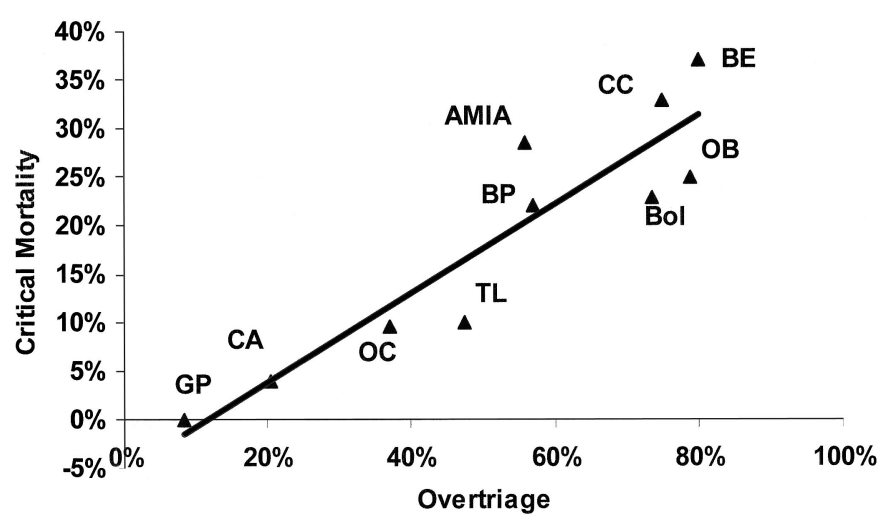

Fig. 1. Graphic relation of overtriage rate to critical mortality rate, in 10 terrorist bombing incidents from 1969 to 1995, derived from data in Table 6. Linear correlation coefficient $(\mathrm{r})=0.92$. GP, Guildford pubs; CA, Craigavon; OC, Oklahoma City; TL, Tower of London; BP, Birmingham pubs; Bol, Bologna; AMIA, Buenos Aires; OB, Old Bailey; CC, Cu Chi; BE, Beirut.

outcome in mass casualty disasters, over and above logistic and economic considerations.

An urban location enhances the value of triage accuracy in disasters because of the immediate availability of extensive medical resources to apply to critically injured victims, and is another reason why such locations tend to be associated with better outcome than isolated locations. In the latter settings, as in Beirut and $\mathrm{Cu} \mathrm{Chi}$, triage accuracy has less impact on survivor outcome. Overtriage becomes a necessity, because all casualties must be evacuated, usually over long distances, because of the absence of any depth to local medical resources, resulting in delayed treatment of many critically injured, which contributes to the higher mortality in these settings (Table 6)..$^{32,33}$

The wide variation in published immediate mortality, critical injury, overtriage, and critical mortality rates reflects the many variables in individual disasters that may affect these rates, and thus survival. The analysis of injury and mortality patterns of past bombing disasters in the above review allows these prognostic factors to be derived (Table 7).

\section{Table 7 Prognostic Factors Affecting Casualty Outcome after Terrorist Bombings}

Magnitude of explosion

Building collapse

Triage accuracy

Time interval to treatment

Indoor vs. open-air

Urban vs. isolated setting

Anatomic injuries

Immediate presence of surgeons

\section{RESPONDING TO THE PRESENT Adapting Disaster Plans to Reality}

The lessons learned from the past should allow us to improve our planning and response to current incidents and to avoid prior mistakes. Klein and Weigelt ${ }^{53}$ reported their experience with three sequential aircraft crash disasters in Dallas, Texas, over a period of 3 years. As a result of analyzing the problems they encountered, they were able to modify the community and hospital disaster plans to more effectively manage the logistics and medical management of large casualty loads. They found their original plans at a Level I trauma center to be unrealistic and ineffective, a typical finding in most disaster critiques. The major problems they encountered were communications between the disaster scene and hospital, the authority and command structure, security considerations for scene and medical personnel safety, and the organization of medical management, all also typical of most reported disasters. Command was facilitated by establishing two command posts to separate administrative responsibilities from medical management. Communications were secured through protected phone lines controlled by the administrative post, and the use of walkie-talkies, to circumvent the completely overwhelmed hospital phone lines by unrestricted incoming calls. Medical management evolved to a number of small teams sited in designated rooms to evaluate and evacuate patients distributed to them by the triage process. The number of physicians needed for care was substantially reduced, and efficiency of care increased. A postevent debriefing critique of all involved participants was held within 24 hours of the incident to review the problems, which led to revision of the plan to better cope with future events.

Hirshberg and coworkers ${ }^{54}$ described a disaster simulation technique using a computer program to determine the effectiveness of a hospital disaster plan. They found that the planned number of surgeons and operating rooms and the necessary level of triage accuracy were overestimated, and that the number of resuscitation beds and the extent of radiography and computed tomographic scan use were underestimated in their disaster plans after simulating a mass casualty scenario. Others have reported this as well. ${ }^{43,53}$ They found no improvement in outcome by reducing overtriage from $50 \%$ to $25 \%$, which indicates that triage need not necessarily be performed by the most experienced physicians, who may be used more effectively in direct patient care. They emphasized the importance of restricting laboratory and radiology testing in this setting, which is largely overused even in ordinary circumstances, but may significantly hamper casualty flow, and jeopardize lives, in disasters. ${ }^{2}$

\section{Principles of Scene Triage}

Effective triage is necessary to screen out the great majority of noncritically injured survivors of terrorist bombings, who typically are the first to reach the hospital in large numbers, and could overwhelm resources immediately. ${ }^{1,2,9,35,47}$ In contrast to 
normal practice, casualties must be kept out of hospitals to the greatest extent possible. The time of greatest danger to orderly casualty handling, and of risk of hospital overload, is in the immediate aftermath of a bombing, a period of chaos. A rapid institution of strong authority and leadership over the care of victims is necessary to avoid loss of life in this initial phase of disaster management, and this is only possible with preplanning and rehearsal. $2,5,23,26,53$ If there is any biologic, chemical, or radiation contamination involved in the disaster, this period could lead to the hospital itself being shut down if prompt control is not established.

Triage sites must be established in large open areas, and must be located outside of the hospital. It is recommended that a second triage site be established to further screen initially evaluated casualties to enhance triage accuracy, and to ensure that only those needing hospitalization are admitted. ${ }^{3,5,6,9}$ It is also important that the triage sites be located away from the bombing scene, to avoid the risk of a second bomb blast, which terrorists have used commonly to take out initial survivors, rescue personnel, and unwitting onlookers. ${ }^{2,5}$ The devastation and further loss of life of this second-hit practice was demonstrated in the Halifax and Texas City explosions, as well as in the September 11, 2001, World Trade Center disaster, when hundreds of firefighters and other rescuers were killed, after responding to the initial incidents, by a delayed blast or building collapse. In Beirut, it took the form of sniper fire that impeded the rescue efforts for several hours, during which time a number of survivors died before rescue. ${ }^{32}$ The destruction of the onshore medical facilities in Beirut and Halifax also emphasizes the danger of placing medical assets in positions of jeopardy. A second explosion remains a common tactic in the current suicide bombings in the Middle East. ${ }^{2}$ This risk mandates that medical personnel, as well as surviving casualties, stay away from the bombing site, where they have nothing more to offer than nonmedical assets, who, unlike medical personnel, are trained for the dangers involved. ${ }^{6}$ Protection of medical assets must be a major priority of disaster management.

The clear relation between triage accuracy and casualty outcome (Fig. 1) emphasizes the critical importance of the triage process. The triage officer must have experience and expertise in trauma management to identify rapidly those critical injuries requiring immediate treatment, and to exclude noncritical injuries from this category. Training in the principles of triage and mass casualty handling is a further essential requirement of triage officers, to apply limited medical resources most efficiently. It has been shown that overtriage is minimized when physicians perform field triage, and is increased with nonphysicians in this role. ${ }^{50}$ Cook and coworkers $^{51}$ further demonstrated that physiologic and anatomic criteria are superior to mechanism indicators in reducing overtriage, and that minimizing overtriage can be done without compromising undertriage. The triage officer must have absolute authority to decide treatment priority for casu- alties in the field, and must coordinate transport of victims to the appropriate medical facilities. ${ }^{2,53}$

\section{Medical Management and Casualty Flow}

After rescue, treatment of bombing casualties begins at the triage site with rapid stabilization, control of hemorrhage, splinting of fractures, and cleaning and covering wounds. Immediate determination of concomitant radiation, chemical, or biologic contamination must be made and a decontamination process instituted before victims reach the hospital. Extensive or definitive treatment should not be performed at this stage. ${ }^{2,23}$ A systematic method of distribution of casualties from the triage sites among available hospitals and definitive medical facilities must occur according to injury severity and urgency, and with the aim of avoiding any single facility from being overloaded. 7 "Leap-frogging" of hospitals by sequential loads of transported casualties is the method described to achieve this in urban disasters. ${ }^{5,6}$ Also, hospitals should consider a "secondary distribution" of casualties whose definitive treatment may be delayed, for such things as soft tissue and skeletal injuries, so as to allow more attention to critical victims. $^{2}$ Evacuation of casualties to distant facilities by air transport may be necessary with large casualty loads, and in isolated environments.

The criteria for expectant injuries that should not be treated must be defined as quickly as possible for those directing the medical management, according to the nature of the bombing, the estimated casualty burden, and the resources available. Unresponsive patients should be assumed to be dead and should not be resuscitated. Closed chest compressions and emergency room thoracotomies should be forbidden. Serious consideration must be given to avoiding blood transfusions and endotracheal intubation in view of their substantial resource requirements. ${ }^{2}$ Although in the urban setting there are generally adequate resources for airway and ventilator support, this may not be true in more rural and isolated settings.

Casualties assigned to immediate hospital care must be assessed and treated as quickly as possible, receiving only "minimal acceptable care" during the initial phase of casualty influx. ${ }^{2}$ It is essential that casualty flow always move forward, and briskly (Table 1). Backward or slow flow will bring chaos while casualty influx continues. All evaluated and stabilized patients must be moved to new areas to make room for new casualties. Only those with immediately lifethreatening surgical issues should be transported to the operating room in this phase, and surgery must be truncated according to the principles of damage control, allowing rapid turnover of rooms. Plain radiographs and laboratory blood work should be greatly restricted, and major diagnostic tools such as angiography, magnetic resonance imaging, computed tomographic scanning, and other contrast studies must be avoided. These modalities are impractical in disaster management, and will severely hamper efficient casualty evaluation and flow. On the other hand, sonography has proven to 
be an effective screening tool for abdominal injuries in mass casualty disasters. ${ }^{2,55}$ Crossmatching of blood must be avoided, as it is expensive and largely unnecessary in bombing disasters. ${ }^{53,54}$ Many interventions can be applied on the basis of clinical findings alone, such as tube thoracostomy and laparotomy. Only when the casualty influx subsides should physicians reassess all evaluated casualties more completely, and begin considering treatment or evacuation of those in the delayed and expectant categories. At this time there will be a better understanding of available resources.

Primary blast lung injury poses a major challenge in treatment, and fortunately occurs in only a small minority of bombing survivors. It presents as acute respiratory failure, and its radiographic findings are similar to pulmonary edema. Oxygenation must be supported, but positive pressure should be avoided if possible because of the tendency to induce air embolism. Noninvasive ventilatory support should be tried initially. If intubation is necessary, high-frequency jet ventilation, independent lung ventilation, or volume-controlled ventilation should be considered to reduce ventilation pressures. The classic presenting triad of apnea, bradycardia, and hypotension must be treated, and resuscitative fluids should be judiciously restricted. ${ }^{2,56}$

Most injuries in bombing survivors are caused by secondary and tertiary blast effects, which cause a typical spectrum of traumatic injuries with which surgeons are familiar. Most of these are noncritical soft tissue and skeletal injuries, but tend to be extensive and contaminated and require substantial debridement and multiple procedures. Burns are usually superficial, and caused by the brief thermal flash of the explosion. ${ }^{57} \mathrm{~A}$ liberal approach is warranted to early abdominal, head, and thoracic operations in those with critical injuries to these anatomic areas in view of their high specific mortality. This emphasizes the importance of immediate availability of surgeons and surgical support personnel and facilities to minimize morbidity and mortality of bombing survivors. $^{32,33,58}$

\section{Record-Keeping}

Written documentation of all findings and interventions in the victims of bombing disasters is an essential part of disaster management. It is the only reliable means by which continuity of care can be maintained and redundant triage and treatment can be avoided as patients are transported through the successive echelons of care mandated in mass casualty scenarios. ${ }^{1}$ These records should be strapped to the patient to avoid being lost. Plastic lamination has been suggested to protect against moisture. The forms that are used should be familiar to the caregivers as much as possible to avoid the time required to learn new forms. ${ }^{53}$

Accurate records also allow the retrospective assessment of casualty injuries and outcome that is so necessary for critical analysis of the administrative and medical management of an individual disaster. ${ }^{9,32,33,53}$ It facilitates the postevent debriefing and critique that has been recommended to assess and revise disaster plans. ${ }^{53}$ All deaths among survivors should be analyzed to determine the quality of medical care, especially among cases of undertriage or deaths among noncritically injured victims. Any immediate care provided to expectant injuries should be considered overtriage, and the inevitable death of these patients will result in raising the critical mortality rate as a result. Such mistriage could result in unnecessary loss of life among more salvageable patients. Mortality among properly triaged expectant injuries should be categorized as immediate deaths, as they never received medical care, and therefore should not skew the critical mortality rate as a measure of medical care. This information can be compared with reports of other disasters to obtain a broader perspective on the quality of disaster management provided, and then can be used to publish and disseminate the results to allow others to learn from an individual experience.

\section{PREPARING FOR THE FUTURE}

The most important means of preparing for the large casualty loads of bombing disasters is to understand the patterns of injuries and logistical problems that result. Only the published experience of those who have confronted actual disasters can provide this knowledge, because of the rarity of mass casualty events. We must read this literature. This emphasizes the obligation of all who are involved in a disaster to collate and analyze the results of casualty care according to the template suggested in this review, compare these results to other similar events, and publish the findings.

The advance formulation of a disaster plan is essential for the successful management of mass casualties, because these incidents are unpredictable in their timing and location. ${ }^{5,44}$ In order that the plan be relevant and workable, it must be based on the published experience to the extent possible. Surgical capability must be a central feature of these plans. An effective disaster plan must incorporate all community and hospital assets that will be required for the proper handling of mass casualties. These plans should be rehearsed regularly through simulation drills, and a critique of these drills should lead to appropriate revision of the plans. A postevent debriefing of involved personnel is important soon after a disaster, so as to revise the disaster plans according to the problems encountered. ${ }^{53}$ Above all, flexibility must be built into these plans to allow adaptation to the unique circumstances characteristic of every disaster, but still within the context of the broad principles reviewed above. We must all have the "imagination" to be prepared for the most unexpected forms of attack to provide the best care for the victims.

Another necessity for future preparations for bombing disasters is that physicians, and especially surgeons, become more involved in the planning process than they have been historically. Trauma surgeons, trauma centers, and trauma organizations are uniquely suited to leadership roles in the planning, organization, and implementation of disaster care. We in the Eastern Association for the Surgery of Trauma (EAST) have recognized the importance of this long-ne- 
glected area of trauma, and have committed ourselves to the education of surgeons and other health care workers in disaster management principles through our Military Medicine and Disaster Management ad hoc committees. This commitment represents a major advance of the fundamental mission of EAST, that of promoting the care and welfare of the injured patient, into the frontiers of the 21 st century.

\section{REFERENCES}

1. Rignault DP. Recent progress in surgery for the victims of disaster, terrorism and war. World J Surg. 1992;16:885-887.

2. Stein M, Hirshberg A. Medical consequences of terrorism: the conventional weapon threat. Surg Clin North Am. 1999;79:15371552.

3. Slater MS, Trunkey DD. Terrorism in America: an evolving threat. Arch Surg. 1997;132:1059-1066.

4. Eiseman B. Combat casualty management for tomorrow's battlefield: urban terrorism. J Trauma. 2001;51:821-823.

5. Jacobs LM, Ramp JM, Breay JM. An emergency medical system approach to disaster planning. J Trauma. 1979;19:157-162.

6. Jacobs LM, Goody M, Sinclair A. The role of a trauma center in disaster management. J Trauma. 1983;23:697-701.

7. Ammons MA, Moore EE, Pons PT, et al. The role of a regional trauma system in the management of a mass disaster: an analysis of the Keystone Colorado chairlift accident. J Trauma. 1988;28:14681471.

8. American College of Surgeons, Committee on Trauma. Resources for Optimal Care of the Injured Patient. Chicago, IL: American College of Surgeons; 1998.

9. Caro D. Major disasters. Lancet. 1974;2:1309-1310.

10. Hadden WA, Rutherford WH, Merrett JD. The injuries of terrorist bombing: a study of 1532 consecutive patients. Br J Surg. 1978; 65:525-531.

11. Adler J, Golan E, Golan J, et al. Terrorist bombing experience during 1975-79: casualties admitted to the Shaare Zedeck Medical Center. Isr J Med Sci. 1983;19:189-193.

12. Cooper GJ, Maynard RL, Cross NL, et al. Casualties from terrorist bombings. J Trauma. 1983;23:955-967.

13. MacPherson WG. History of the Great War, Medical Services, General History. Vol 3. London: His Majesty's Stationery Office; 1924.

14. Stapczynski JS. Blast injuries. Ann Emerg Med. 1982;3:287-293.

15. Phillips YY. Primary blast injuries. Ann Emerg Med. 1986;15:14461450 .

16. Zuckerman S. Experimental study of blast injuries to the lungs. Lancet. 1940;2:219-238.

17. Rawlins JSP. Physical and pathophysiological effects of blast. Injury. 1977;9:313-320.

18. Hill JF. Blast injury with particular reference to recent terrorist bombing incidents. Ann R Coll Surg Engl. 1979;61:4-11.

19. Clemedsson CJ. Blast injury. Physiol Rev. 1956;36:336-354.

20. Huller J, Bazini Y. Blast injuries of the chest and abdomen. Arch Surg. 1970;100:24-30.

21. Leibovici D, Gofrit ON, Stein M, et al. Blast injuries: bus versus openair-bombings - a comparative study of injuries in survivors of open-air versus confined-space explosions. J Trauma. 1996;41:1030-1035.

22. Candole CA. Blast injury. Can Med Assoc J. 1967;96:207-214.

23. Brismar B, Bergenwald L, The terrorist bomb explosion in Bologna, Italy, 1980: an analysis of the effects and injuries sustained. J Trauma. 1982;22:216-220.

24. Kernaghan L. Halifax explosion. Available at: http://tceplus.com/ halifax.htm. Accessed December 20, 2001.
25. Stephens HW. The Texas City Disaster, 1947. Austin, TX: University of Texas Press; 1947.

26. Berry FB. The medical management of mass casualties: the Scudder Oration on Trauma. Bull Am Coll Surg. 1956;41:60-66.

27. U.S. Department of State. International Terrorism. Selected documents, No. 24. Washington, DC: U.S. Government Printing Office; 1986.

28. Rignault DP, Deligny MC. The 1986 terrorist bombing experience in Paris. Ann Surg. 1989;209:368-373.

29. Karmy-Jones R, Kissinger D, Golocovsky M, et al. Bomb-related injuries. Mil Med. 1994;159:536-539.

30. Scott BA, Fletcher JR, Pulliam MW, et al. The Beirut terrorist bombing. Neurosurgery. 1986;18:107-110.

31. Frykberg ER, Hutton PMJ, Balzer RH. Disaster in Beirut: an application of mass casualty principles. Mil Med. 1987;11:563566.

32. Frykberg ER, Tepas JJ, Alexander RH. The 1983 Beirut airport terrorist bombing: injury patterns and implications for disaster management. Am Surg. 1989;55:134-141.

33. Frykberg ER, Tepas JJ. Terrorist bombings: lessons learned from Belfast to Beirut. Ann Surg. 1988;208:569-576.

34. Henderson JV. Anatomy of a terrorist attack: the $\mathrm{Cu}$ Chi mess hall incident. J World Assoc Emerg Disaster Med. 1986;2:69-73.

35. Biancolini CA, DelBosco CG, Jorge MA. Argentine Jewish Community Institution bomb explosion. J Trauma. 1999;47:728-732.

36. Mallonee S, Shariat S, Stennies G, et al. Physical injuries and fatalities resulting from the Oklahoma City bombing. JAMA. 1996; 276:382-387.

37. Glanz J. In collapsing towers, a cascade of failures. New York Times. November 11, 2001:B1, B11.

38. Pyper PC, Graham WJH. Analysis of terrorist injuries treated at Craigavon Area Hospital, Northern Ireland, 1972-1980. Injury. 1982; 14:332-338.

39. Rutherford WH. Experience in the accident and emergency department of the Royal Victoria Hospital with patients from civil disturbances in Belfast, 1969-1972, with a review of disasters in the United Kingdom, 1951-1971. Injury. 1972;4:189-199.

40. Caro D, Irving M. The Old Bailey Bomb explosion. Lancet. 1973; 1:1433-1435.

41. Tucker K, Lettin A. The Tower of London bomb explosion. BMJ. 1975;3:287-290.

42. Waterworth TA, Carr MJT. Report on injuries sustained by patients treated at the Birmingham General Hospital following the recent bomb explosions. BMJ. 1975;2:25-27.

43. Feliciano DV, Anderson GV, Rozycki GS, et al. Management of casualties from the bombing at the Centennial Olympics. Am J Surg. 1998;176:538-543.

44. Kennedy TL, Johnston GW. Civilian bomb injuries. BMJ. 1975; 1:382-383.

45. Golan J, Golan E, Adler J, et al. Plastic surgery and civilian casualties due to "terrorist" activities. Ann Plast Surg. 1982;8:359362.

46. Marshall TK. Forensic aspects of terrorism. Ann Acad Med Singapore. 1984;13:32-36.

47. Sklar DP. Casualty patterns in disasters. J World Assoc Emerg Disaster Med. 1987;3:49-51.

48. U.S. Department of Defense. Emergency War Surgery. Washington, DC: U.S. Government Printing Office; 1975.

49. Champion HR, Sacco WJ. Trauma severity scales. In: Maull KI, ed. Advances in Trauma. Vol 1. Chicago: Yearbook Medical Publishers; 1986:1-20.

50. Champion HR, Sacco WJ, Gainer PS, et al. The effect of medical direction on trauma triage. J Trauma. 1988;28:235-239. 
51. Cook CH, Muscarella P, Praba AC, et al. Reducing overtriage without compromising outcomes in trauma patients. Arch Surg. 2001;136:752-756.

52. American College of Surgeons, Committee on Trauma. Field categorization of trauma patients (field triage). Bull Am Coll Surg. 1986;71:17-21

53. Klein JS, Weigelt JA. Disaster management: lessons learned. Surg Clin North Am. 1991;71:257-266.

54. Hirshberg A, Stein M, Walden R. Surgical resource utilization in urban terrorist bombing: a computer simulation. J Trauma. 1999; 47:545-550.
55. Sarkisian AE, Khondkarian RA, Amirbekian NM, et al. Sonographic screening of mass casualties for abdominal and renal injuries following the 1988 Armenian earthquake. J Trauma. 1991;31:247250.

56. Guy RJ, Kirkman E, Watkins PE, et al. Physiologic responses to primary blast. J Trauma. 1998;45:983-987.

57. Rosenberg B, Sternberg N, Zagher V, et al. Burns due to terroristic attacks on civilian populations from 1975-1979. Burns. 1982;9:2123.

58. Bellamy RF. The medical effects of conventional weapons. World J Surg. 1992;16:888-892.

\section{The 2002 Tanner-Vandeput-Boswick Burn Prize Awarded}

The International Burn Foundation is pleased to announce the 2002 Tanner-Vandeput-Boswick Burn Prize will be awarded to Dr. Charles R. Baxter of Dallas, Texas. The award consists of a cash prize in excess of $\$ 150,000$, a plaque, and a gold and diamond pin designed by the late Dr. J.C. Tanner. Presentation was made August 12, 2002 at the Congress of the International Society for Burn Injuries in Seattle, WA.

Dr. Baxter has had a career of over 40 years in the field of burn care at the University of Texas SW Medical Center in Dallas. He has been involved in research in pathophysiology of burn injury (especially the cause and treatment of burn shock), control of infection, surgical care, early skin grafting, nutritional and metabolic response, treatment, and many other phases of burn care.

Through his clinical and laboratory work he has contributed to the improvement of burn care throughout the world. He developed the concept of the "burn team" and established one of the first civilian burn units in the United States at Parkland Hospital in Dallas. He developed a NIH-sponsored Master's Degree Nurse Specialist program at UTSW in Dallas.

In 1980 he started the Journal of Burn Care \& Rehabilitation and was its editor for the first 17 years; the Journal is now the official publication of the American Burn Association. He was a founding member of the ABA, received the ABA Allen Distinguished Service Award, and most recently received the only Life Achievement Award ever given by the ABA. To his many accomplishments and awards is now added the 2002 Tanner-Vandeput-Boswick Burn Prize. 